\title{
PENERAPAN BEHAVIOR THERAPY UNTUK MENINGKATKAN KEPATUHAN ASUPAN CAIRAN PADA PASIEN GAGAL GINJAL YANG MELAKUKAN HEMODIALISIS
}

\author{
Rima Mustika ${ }^{1}$, Denrich Suryadi², Indriyani Virginia ${ }^{3}$ \\ ${ }^{1}$ Fakultas Psikologi, Universitas Tarumanagara Jakarta \\ Email: rimamustika2591@gmail.com \\ ${ }^{2}$ Fakultas Psikologi, Universitas Tarumanagara Jakarta \\ Email: angiedenrich@yahoo.com \\ ${ }^{3}$ Fakultas Psikologi, Universitas Tarumanagara Jakarta \\ Email: indriyani_virginia@yahoo.com
}

\begin{abstract}
ABSTRAK
Ginjal adalah sepasang organ saluran kemih yang terletak di rongga retro perituneal bagian atas. Ginjal orang dewasa memiliki panjang $12-13 \mathrm{~cm}$ dengan lebar $6 \mathrm{~cm}$ dan berat sekitar 120-150gram. Fungsi reguler ginjal adalah mengangkut sisa - sisa metabolisme tubuh. Ketika ginjal tidak mampu lagi berfungsi, maka ginjal mengalami kegagalan gagal ginjal adalah suatu kondisi dimana fungsi ginjal mengalami penurunan sehingga tidak mampu lagi untuk melakukan filtrasi sisa metabolisme tubuh. Penyakit ini terus berkembang secara perlahan hingga fungsi ginjal semakin memburuk. Hal ini menyebabkan penumpukan dalam tubuh berupa cairan yang apabila tidak dikeluarkan akan meracuni tubuh. Terapi yang dapat dilakukan adalah dengan melakukan hemodialisis. Hemodialisis (HD) adalah tindakan yang dilakukan untuk mencuci darah dengan tujuan membantu mengeluarkan zat - zat yang tidak diperlukan tubuh karena ginjal tidak dapat melaksanakan tugasnya lagi. Pasien tersebut juga harus menjaga asupan cairan harian agar tidak kelebihan cairan dalam tubuh. Untuk itu, dokter menganjurkan batasan asupan cairan yang harus dipatuhi. Namun, terkadang pasien sering tidak mematuhi hal ini karena sering merasa haus dan tidak dapat mengontrol asupan cairannya. Terapi psikologis yang dapat dilakukan adalah dengan behavior therapy. Tujuan dari intervensi behavior therapy yang dilakukan adalah untuk membantu subjek agar dapat memahami dan disiplin dalam memenuhi asupan cairan hariannya. Teknik yang digunakan adalah memberikan intervensi dengan modelling therapy dan dilakukan pada satu pasien (single-subject design) yang melakukan hemodialisis di Klinik X. Metode tersebut merupakan salah satu desain penelitian eksperimental yang digunakan untuk membantu mengidentifikasi efektivitas dari suatu intervensi. Hasil dari intervensi ini diharapkan subjek dapat memahami dengan baik kondisinya dengan bantuan behavior therapy sehingga subjek menjadi sadar akan pentingnya mentaati aturan asupan cairan hariannya. Terdapat peningkatan kepatuhan pada pasien setelah intervensi diberikan. Dapat dikatakan pendekatan behavior therapy dengan teknik modelling dapat membantu pasien untuk meningkatkan kepatuhan pasien akan asupan cairan hariannya.
\end{abstract}

Kata kunci: Behavior therapy, teknik modelling, gagal ginjal, hemodialisis, asupan cairan.

\section{PENDAHULUAN}

\section{Latar Belakang}

Gagal ginjal terjadi ketika ginjal tidak mampu untuk mengangkut sisa - sisa metabolik tubuh sebagai fungsi sebenarnya. Sehingga sisa - sisa tersebut menumpuk dalam cairan tubuh dan menyebabkan gangguan fungsi endokrin dan metabolik, cairan, elektrolit serta asam - basa (Suharyanto \& Madjid, 2009). Hal ini mengakibatkan ginjal mengalami penurunan fungsi. Penyakit ini dapat terus berkembang secara perlahan - lahan sehingga fungsi ginjal semakin memburuk hingga ginjal kehilangan fungsinya (Price \& Wilson, 2006). Ginjal merupakan organ penting yang berfungsi menjaga komposisi darah dengan mencegah menumpuknya sisa - sisa metabolisme tubuh dan mengendalikan keseimbangan cairan dalam tubuh (Riskesdas, 2013). Prevalensi gagal ginjal kronis meningkat seiring dengan meningkatnya jumlah penduduk usia lanjut dan kejadian penyakit diabetes melitus serta hipertensi. Dalam Global Burden of Disease 
(2010) gagal ginjal kronis merupakan penyakit dengan angka kematian tinggi yang menduduki peringkat 27 di dunia pada tahun 1990.

Peringkat ini semakin tinggi sehingga berpindah pada urutan 18 pada tahun 2010. Penyakit gagal ginjal merupakan ranking kedua pembiayaan terbesar dari BPJS kesehatan setelah penyakit jantung (Riskesdas, 2013). Kerusakan ginjal ini mengakibatkan permasalahan pada kemampuan dan kekuatan tubuh yang dapat menyebabkan aktivitas kerja bermasalah, mudah merasa lelah, lemas sehingga kualitas hidup pasien menurun (Bruner \& Suddarth, 2001). Hasil survey yang dilakukan oleh Perhimpunan Nefrologi Indonesia (Pernefri) memperkirakan adanya $12,5 \%$ dari populasi penduduk Indonesia atau sekitar 25 juta mengalami penurunan fungsi ginjal (Riskesdas, 2013). Jumlah penderita gagal ginjal kronik berdasarkan diagnosis dokter di Indonesia sebesar $0,2 \%$.

Gagal ginjal kronik merupakan penurunan fungsi ginjal yang berlangsung lama dan bertahap, bersifat progresif dengan kreatinin klirens (Sidabutar, 1983). Gagal ginjal adalah suatu kondisi dimana ginjal tidak berfungsi dengan normal. Oleh karena itu diperlukan terapi pengganti untuk membawa sisa-sisa metabolisme tubuh. Terapi pengganti ini dilakukan untuk membantu pasien mempertahankan hidup sampai beberapa tahun lamanya. Salah satu terapi nya adalah dengan melakukan hemodialisis (HD). Hemodialisis (HD) bertujuan menggantikan fungsi ginjal sehingga dapat memperpanjang kelangsunggan hidup dan memperbaiki kualitas hidup pada penderita gagal ginjal kronik. Hemodialisis adalah suatu proses terapi pengganti ginjal dengan menggunakan selaput membran semi permeabel (dializer), yang berfungsi seperti nefron sehingga dapat mengeluarkan produk sisa metabolisme dan mengoreksi gangguan keseimbangan cairan dan elektrolit pada pasien gagal ginjal (Hayani, 2014).

Tujuan dilakukan hemodialisis adalah untuk mengambil zat-zat nitrogen yang bersifat toksik dari dalam tubuh pasien ke dializer tempat darah tersebut dibersihkan dan kemudian dikembalikan ke tubuh pasien (Cahyaningsih, 2009). Selama melakukan proses hemodialisis, terdapat aturan yang harus dipatuhi oleh pasien yakni anjuran asupan cairan harian yang tidak melebihi $600 \mathrm{ml}$ perhari. Namun, para pasien masih melanggar anjuran ini sehingga menyebabkan pembengkakan pada bagian tubuh tertentu pasien. Pada pasien gagal ginjal yang menjalani hemodialisis sering mengalami kelebihan volume cairan dalam tubuh. Hal ini disebabkan penurunan fungsi ginjal dalam mengekresikan cairan. Salah satu faktor yang dapat mempengaruhi pasien dalam kelebihan asupan cairan adalah faktor pengetahuan yang minim. Pengetahuan tersebut berupa adanya kondisi pasien yang tidak memungkinkan karena adanya permasalahan personal yang berakibat pada perilaku pola makan sehingga subyek sering melanggar aturan asupan cairan yang dianjurkan.

Faktor yang mempengaruhi kepatuhan ini diantara lain adalah faktor pasien dan faktor pelayanan kesehatan. Faktor pasien diantaranya adalah karakteristik pasien seperti usia, jenis kelamin, ras, status perkawinan, pendidikan, lamanya sakit, tingkat pengetahuan, status bekerja, persepsi, motivasi, dan kebiasaan merokok. Sedangkan faktor pelayanan kesehatan meliputi fasilitas hemodialisis, akses menuju tempat hemodialisis, biaya, waktu, dan keterampilan petugas. Di Indonesia, terdapat sebanyak 100-150 tiap 1 juta penduduk per tahun yang mengalami gagal ginjal. Pada tahun 2000 terdapat sebanyak 2.617 pasien yang melakukan hemodialisis dengan beban biaya yang ditanggung oleh Askes sebesar Rp. 32,4 Milyar. Pada tahun 2004 menjadi 6.314 kasus dengan biaya Rp. 67,2 Milyar.

Selain melakukan penanganan secara medis dengan melakukan hemodialisis, pasien juga dapat melakukan penanganan secara psikologis. Hal ini berkaitan dengan kondisi psikis dari pasien 
seperti mengalami masalah keuangan, masalah keluarga yang dapat menimbulkan dampak pada penyakit yang sedang dialami oleh pasien. Hal ini terkait dengan faktor dari pasien yang sulit untuk mematuhi aturan asupan cairan perharinya. Adapun teknik yang dapat dilakukan salah satunya adalah dengan behavior therapy. Albert Bandura yang diambil dari buku Feist dan Feist (2008) menekankan bahwa individu dapat belajar melalui observasi tanpa harus terlibat dalam perilaku yang bersangkutan. Proses belajar ini dinamakan dengan observational learning. Inti dari observational learning adalah modelling. Pembelajaran melalui modelling melibatkan penambahan dan pengambilan dari suatu perilaku yang diobservasi dan mengeneralisasikan hasil observasi ke dalam perilaku. Dengan kata lain, proses modelling melibatkan proses kognitif dan tidak sekedar hanya proses imitasi saja. Proses modelling melibatkan merepresentasikan informasi dan menyimpannya untuk digunakan di masa depan (Feist \& Feist, 2008).Berdasarkan paparan diatas, maka dapat diketahui bahwa kepatuhan terhadap anjuran asupan cairan pada pasien gagal ginjal yang menjalani hemodialisis merupakan suatu hal yang penting.

\section{Rumusan Masalah}

Apakah teknik modelling therapy dapat membantu dalam merubah pola makan sesuai anjuran asupan cairan pada pasien gagal ginjal yang melakukan hemodialisis ?

\section{METODE PENELITIAN Partisipan}

Seorang pria usia dewasa tengah berusia 48 tahun dengan gangguan ginjal kronik yang mengalami perceraian, lama sakit empat tahun, dan memiliki kebiasaan merokok. Partisipan mengeluhkan adanya sakit pada kaki, nafas pendek, tidak dapat tidur di malam hari, mudah lelah, dan mudah stres yang disebabkan oleh ketidakpatuhannya terhadap anjuran asupan cairan harian sesuai dengan petunjuk dokter. Berdasarkan hasil observasi yang dilakukan, subyek memiliki kelebihan cairan yang berpusat pada perutnya. Hal ini menyebabkan perut subyek terlihat lebih besar dibandingkan dengan badannya yang kurus. Subyek mengatakan bahwa selama proses pencucian darah, subyek lebih senang tidur sampai prosesnya selesai. Hal ini karena subyek mengalami kesulitan untuk tidur ketika berada di rumah. Adanya hal terebut menyebabkan subyek menjadi tidak mematuhi aturan asupan cairan hariannya. Subyek tetap mengonsumsi cairan lebih dari yang dianjurkan oleh dokter.

\section{Experimental design}

Penelitian ini termasuk ke dalam penelitian single-subject experimental designs. Jenis penelitian single-subject experimental designs merupakan salah satu design penelitian eksperimental yang digunakan untuk membantu mengidentifikasi efektivitas dari suatu intervensi (Horner et al., 2005 dalam Byiers et al., 2012). Berbeda dengan jenis penelitian eksperimental lainnya, pada singlesubject experimental designs jumlah partisipan hanyalah satu atau hanya sedikit subyek.

\section{Setting dan perlengkapan}

Intervensi dilakukan di klinik hemodialisa $X$, tepatnya di ruang konsultasi dokter yang berada di lantai 1. Pada ruangan ini telah disiapkan peralatan berupa laptop, catatan harian, dan alat tulis.

\section{Prosedur}

Dalam behavior therapy, disebutkan bahwa observational learning memiliki inti yakni modeling. Modeling adalah teknik terapi yang dilakukan ketika klien mengobservasi perilaku orang lain dan menggunakan observasi tersebut (Sharf, 2014). Belajar bagaimana model mencontohkan perilaku dan apa yang terjadi pada model sebagai konsekuensi dari pembelajaran perilaku merupakan 
bagian dari teknik tersebut. Pada behavior therapy, disebutkan adanya lima fungsi dasar dari modeling. Fungsi tersebut adalah teaching, prompting, motivating, reducing anxiety, dan discouraging.

Modeling dapat dilakukan dengan melihat dari suatu demonstrasi seperti melihat seseorang memperagakan suatu perilaku. Kemudian modeling sebagai prompt adalah meniru perilaku tersebut. selanjutnya perilaku tersebut diberikan motivasi untuk terus muncul. Setelah itu klien dapat merasakan reducing anxiety dengan menerapkan perilaku pada dirinya sendiri. Tahap discouraging adalah melanjutkan perilaku yang sudah ada pada diri klien. Pada bagian ini terdapat lima fungsi yakni live modelling, symbolic modelling, self-modelling, participant modelling, dan covert modelling.

Live modelling adalah teknik yang digunakan dengan cara melihat model untuk mecontohkan suatu perilaku. Biasanya model mencontohkan perilaku beberapa kali dan setelahnya klien mengulang perilaku yang telah diobservasi tersebut beberapa kali (Sharf, 2014). Symbolic modelling adalah teknik yang digunakan dengan menggunakan alat bantu seperti video, foto, buku dan permainan mengenai perilaku yang akan dimunculkan. Self- modelling adalah teknik yang digunakan dengan merekam perilaku klien yang sudah diobservasi untuk ia observasi sendiri lebih lanjut. Participant modeling menggunakan terapis sebagai model yang menunjukkan suatu perilaku dan klien dapat dipandu untuk menggunakan perilaku tersebut. Covert modelling dilakukan dengan cara terapis menggambarkan suatu situasi kepada klien agar klien memiliki bayangan akan situasi tersebut.

\section{Intervensi}

Sesi 1 dilakukan pada tanggal 26 Mei 2017 di ruang hemodialisa Klinik X. Intervensi dilaksanakan pada pukul 09.00 sampai dengan pukul 10.30. Pada intervensi ini, pemeriksa menjelaskan tentang kegiatan yang akan dilakukan pada hari ini, yaitu memberikan psikoedukasi kepada subyek mengenai hubungan antara stres yang dialami dengan mulut yang kering sehingga subyek merasa haus dan akhirnya minum lebih dari anjuran dokter yakni $600 \mathrm{ml}$ sehari. Subyek menceritakan bahwa stres yang ia alami karena adanya permasalahan adik laki - lakinya. Untuk mengalihkan pikirannya, subyek sering berkumpul dengan tetangga dekat rumah yang merupakan pensiunan. Subyek sering bercerita tentang berbagai macam hal dengan para pensiunan ini dan hal tersebut membuat subyek menjadi kembali bersemangat.

Sesi 2 dilaksanakan pada tanggal 29 Mei 2017 di ruang hemodialisa Klinik X. Intervensi dimulai pada pukul 9.30 hingga 11.30. Pada sesi ini, pemeriksa melakukan konseling dengan menanyakan aktivitas harian subyek. Kemudian pemeriksa memutarkan video mengenai proses kerja ginjal, hingga video mengenai penyebab dari stres yang dialami oleh seseorang. Subyek memberikan feedback kepada pemeriksa mengenai video yang telah ditunjukkan. Subyek mengatakan ia baru mengetahui bahwa stres yang ia alami dapat menyebabkan subyek menjadi mudah haus karena mulutnya yang kering. Subyek menceritakan aktivitasnya selama berada di rumah yakni ketika bangun pagi subyek melakukan olahraga ringan selama beberapa menit di halaman rumah. Setelah itu subyek lebih banyak berkumpul dengan teman - teman komplek yang merupakan pensiunan dan melakukan sharing.

Sesi 3 dilakukan pada tanggal 2 Juni 2017 di ruang hemodialisa Klinik X, pada pukul 10.00 hingga 11.30. Pada sesi ini pemeriksa melakukan konseling dengan menanyakan kembali aktivitas yang dilakukan klien selama berada di rumah. Kemudian pemeriksa melakukan review catatan asupan makanan selama tidak melakukan hemodialisa bersama klien. Klien masih sulit untuk mengurangi 
rokok ketika sedang sharing bersama teman - temannya. Pemeriksa meminta klien untuk mengurangi rokok dari yang biasanya bisa mencapai 10 batang sehari menjadi 6 batang sehari sesuai dengan persetujuan klien.

Sesi 4 dilakukan pada tanggal 9 Juni 2017 di ruang hemodialisa Klinik X pada pukul 09.30 hingga 11.00. Pada sesi ini pemeriksa melakukan review catatan asupan pola makan klien dan catatan rokok yang dikonsumsi oleh klien. Klien ditunjukan video mengenai bahaya merokok bagi tubuh manusia dan pemeriksa kembali meminta klien untuk mengurangi rokok yang dikonsumsi dengan harapan agar klien dapat berhenti merokok ditambah lagi dengan kondisi saat ini yang sedang sakit ginjal.

Sesi 5 dilakukan pada tanggal 12 Juni 2017 di ruang hemodialisa Klinik X pada pukul 09.00 hingga pukul 10.15. Pada sesi ini pemeriksa melakukan review mengenai pola makan klien dan melakukan evaluasi seluruh sesi yang telah dilakukan bersama klien. Fisik klien yang awalnya membesar di bagian perut karena kelebihan cairan, sudah mulai memunculkan efek berupa bagian perutnya mengalami penyusutan. Klien sudah mampu untuk mengetahui bahwa stres dapat mempengaruhi diri klien untuk melanggar aturan pola makan dan minum sesuai anjuran dokter. Klien sudah mengetahui apa yang harus dilakukan ketika ia merasa stres. Pada sesi ini pemeriksa juga melakukan terminasi dan meminta feedback dari klien.

\section{Evaluasi}

Intervensi yang diberikan kepada klien dapat dikatakan telah bermanfaat bagi klien. Karena klien menjadi merasa lebih dapat mengelola pola makannya dan kini pembengkakan pada tubuh klien mulai berkurang. Klien mengetahui penyebab stres yang dialaminya, maka klien dapat mengatasi rasa stres tersebut karena dapat berpengaruh terhadap pola makan, khususnya asupan cairan yang dianjurkan oleh dokter kepada klien. Intervensi yang diberikan juga telah sesuai dengan rancangan terapi yang telah disusun sebelumnya oleh pemeriksa sehingga tidak ada perubahan pada sesi terapi yang diberikan.

\section{HASIL DAN PEMBAHASAN}

Dalam rancangan intervensi ini dilakukan konseling dengan pendekatan behavior therapy. Pada behavior therapy terdapat teknik observational learning. Teknik tersebut memiliki inti yakni modelling. Modelling adalah teknik terapi yang dilakukan ketika klien mengobservasi perilaku orang lain dan menggunakan observasi tersebut. Pada behavior therapy, disebutkan adanya lima fungsi dasar dari modeling. Fungsi tersebut adalah teaching, prompting, motivating, reducing anxiety, and discouraging. Modelling dapat dilakukan dengan melihat dari suatu demonstrasi seperti melihat seseorang memperagakan suatu perilaku. Kemudian modelling sebagai prompt adalah meniru perilaku tersebut. selanjutnya perilaku tersebut diberikan motivasi untuk terus muncul. Setelah itu klien dapat merasakan reducing anxiety dengan menerapkan perilaku pada dirinya sendiri. Tahap discouraging adalah melanjutkan perilaku yang sudah ada pada diri klien. Pada bagian ini terdapat lima fungsi yakni live modeling, symbolic modeling, self-modeling, participant modeling, dan covert modeling.

Intervensi yang dilakukan dalam penelitian ini adalah konseling dengan symbolic modelling yakni menggunakan video, foto dan buku yang dapat diberikan kepada subyek. Tujuannya adalah agar subyek tidak hanya menirukan perilaku yang ditunjukkan pada symbolic modelling, tetapi juga ia terapkan pada dirinya sendiri. Kemudian subyek di minta untuk menuliskan asupan makanan hariannya dari awal sesi intervensi hingga sesi terakhir intervensi yang kemudian dilakukan 
evaluasi terhadap keseluruhan sesi yang terlah diberikan. Hasil intervensi yang diberikan kepada subyek bertujuan agar subyek mampu untuk mengelola stres yang dimiliki. Stres yang dialami oleh subyek disebabkan oleh tidak adanya aktivitas dan adanya masalah keluarga yang sedang dialaminya. Hal ini dapat mengakibatkan subyek menjadi mudah stres dan menyebabkan subyek merasa mudah haus. Akibatnya, subyek melanggar aturan pola makan yang telah ditentukan oleh dokter yakni $600 \mathrm{ml}$ sehari. Hal ini disebabkan oleh kondisi mulut subyek yang kering karena stres. Saat ini subyek mengisi waktunya dengan berkumpul bersama teman satu kompleknya untuk dapat saling bertukar pikiran dengan teman kompleknya yang merupakan pensiunan. Menurut subyek, para pensiunan ini lebih memiliki banyak pengalaman dari diri subyek. Sehingga subyek merasa mendapatkan banyak pengetahuan dan merasa lebih senang karena mendapatkan teman yang seumuran dengannya. Subyek selama di klinik selalu riang dan ramah terhadap siapa pun dan senang apabila ada yang mengajaknya berbicara.

Tabel 1

Hasil Intervensi Pada Asupan Cairan Partisipan

\begin{tabular}{|c|c|c|}
\hline \multirow{2}{*}{$\frac{\text { Sesi Intervensi }}{\text { Sesi } 1}$} & Kegiatan & Asupan Cairan \\
\hline & Intervensi 1 & Lebih dari $600 \mathrm{ml}$ \\
\hline 1 & Catatan harian 1 & $700 \mathrm{ml}$ \\
\hline 2 & Catatan harian 2 & $800 \mathrm{ml}$ \\
\hline Sesi 2 & Intervensi 2 & $800 \mathrm{ml}$ \\
\hline 1 & Catatan harian 3 & $600 \mathrm{ml}$ \\
\hline 2 & Catatan harian 4 & $700 \mathrm{ml}$ \\
\hline 3 & Catatan harian 5 & $700 \mathrm{ml}$ \\
\hline Sesi 3 & Intervensi 3 & $500 \mathrm{ml}$ \\
\hline 1 & Catatan harian 6 & $700 \mathrm{ml}$ \\
\hline 2 & Catatan harian 7 & $600 \mathrm{ml}$ \\
\hline 3 & Catatan harian 8 & $600 \mathrm{ml}$ \\
\hline 4 & Catatan harian 9 & $650 \mathrm{ml}$ \\
\hline 5 & Catatan harian 10 & $700 \mathrm{ml}$ \\
\hline Sesi 4 & Intervensi 4 & $700 \mathrm{ml}$ \\
\hline 1 & Catatan harian 11 & $650 \mathrm{ml}$ \\
\hline 2 & Catatan harian 12 & $600 \mathrm{ml}$ \\
\hline Sesi 5 & Evaluasi dan terminasi & $600 \mathrm{ml}$ \\
\hline
\end{tabular}




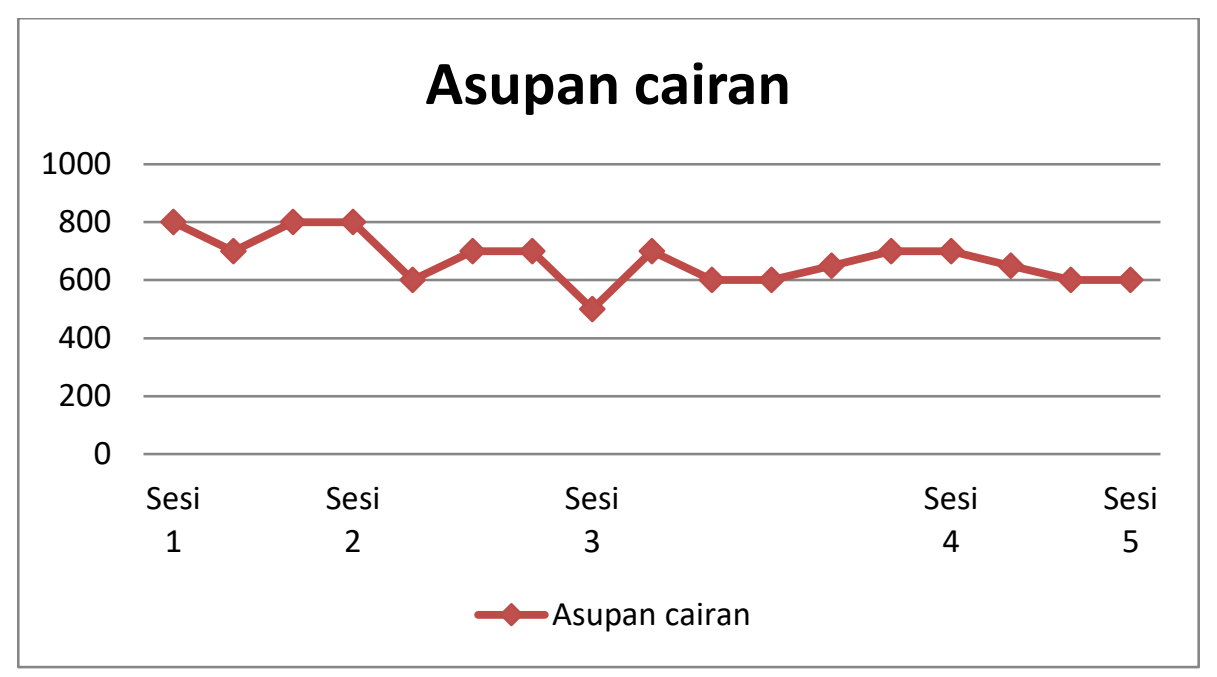

Gambar 1. Hasil Asupan Cairan Partisipan

\section{KESIMPULAN DAN SARAN}

Penanganan yang diberikan kepada subyek adalah modelling dengan pendekatan behaviorism. Tujuan dari penelitian dengan pendekatan tersebut adalah untuk membantu subjek agar dapat memahami dan disiplin dalam memenuhi asupan cairan sesuai dengan anjuran dokter. Dengan demikian, subyek dapat mengetahui bahwa pola makan dan minum subyek yang sering melanggar anjuran dokter diakibatkan adanya stres yang dialami. Selain itu, subyek diharapkan dapat mengisi kegiatan sehari - harinya dengan melakukan aktivitas dan tidak hanya berdiam diri di rumah. Karena hal tersebut dapat menimbulkan stresor bagi diri subyek yang mengakibatkan subyek tidak mematuhi anjuran asupan cairan harian yang telah ditentukan.

Ucapan Terima Kasih (Acknowledgement)

Peneliti mengucapkan terima kasih kepada seluruh pihak yang sudah bersedia berpartisipasi dalam penelitian kali ini.

\section{REFERENSI}

American Psychiatric Association. (2000). Diagnostic and statistical manual of mental disorders (DSM-IV-TR) (4th ed.). Washington, DC: Author.

Bruner \& Suddarth. (2001). Buku ajar keperawatan medikal bedah edisi 8. Jakarta: EGC

Byiers, B.J., Reichle, J., \& Symons, F.J. (2012). Single-Subject Experimental Design For Evidence-Based Practice. American Journal of Speech-Language Pathology. 21, 397-414 Cahyaningsih, D., Niken. (2009). Hemodialisis (Cuci Darah). Yogyakarta: Mitra Cendikia Feist, J., \& Feist, G. J. (2008). Theories of personality (7th ed.). New York: McGraw-Hill. Hayani, Nora. (2014). Hubungan Dukungan Sosial dengan Tingkat Depresi Pasien Gagal Ginjal Kronik yang Menjalani Hemodialisis di RSUD kota Medan, Sumatera Utara

Price,P.A \& Wilson, L.M. (2006). Gout, Pathofisiologi, Konsep Klinis Proses-Proses Penyakit. Jakarta: EGC

Riset Kesehatan Dasar. (2013). Badan Penelitian dan Pengembangan Kesehatan Jakarta, Departemen Kesehatan Jakarta 
Sharf, R. S. (2014). Theories of psychotherapy and counseling: Concepts and cases (6th. Ed.). Boston: Cengage Learning.

Sidabutar. (1983). Gagal ginjal kronik: Ilmu penyakit dalam, Jilid II. Buku Kedokteran. Jakarta: EGC

Smeltzer \& Bare. (2013). Buku ajar keperawatan medikal bedah bruner \& suddarth Edisi 8. Jakarta: EGC

Suharyanto \& Madjid. (2009). Asuhan keperawatan klien dengan gangguan sistem perkemihan. Jakarta: Trans Info Media

Syamsiah, N. (2011). Faktor - faktor yang berhubungan dengan kepatuhan pasien CKD yang menjalani hemodialisis di RSPAU DR. Esnawan Antariksa Halim Perdana Kusuma Jakarta 